\section{ScienceDirect}

Materials Today: Proceedings 16 (2019) 2333-2340

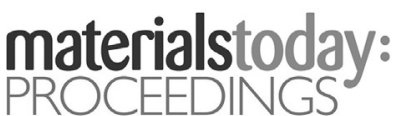

www.materialstoday.com/proceedings

Bio-CAM 2017

\title{
Clinical performance of restorative materials in primary molar teeth
}

\author{
N. A. Harun ${ }^{\mathrm{a}}$, Munirah Yaacobª ${ }^{\mathrm{a}}$ Mohamad Shafiq Aizuddin Abdul `Alim , Saifullah Ghazali \\ Nik Khairul Azmi Nik Khairuzaman ${ }^{\text {d }}$ \\ ${ }^{a}$ Kulliyyah of Dentistry, IIUM Kuantan Campus, International Islamic University Malaysia, Bandar Indera Mahkota, 25200 Kuantan, \\ Pahang, Malaysia. \\ ${ }^{b}$ Klinik Pergigian Pakar, Hospital Tengku Ampuan Afzan, Jalan Tanah Putih, 25200 Kuantan, Pahang, Malaysia. \\ ${ }^{c}$ Klinik Pergigian Bandar Sungai Petani, Jalan Badlishah, 08000 Sungai Petani, Kedah, Malaysia. \\ ${ }^{d}$ Klinik Pergigian Kuala Krai, Klinik Kesihatan Bandar, 18000 Kuala Krai, Kelantan, Malaysia.
}

\begin{abstract}
The aim of this study is to determine the clinical performance of primary molar restorations placed among paediatric patients at the Polyclinic, Kulliyyah of Dentistry, IIUM. A total of 99 primary molar restorations were evaluated clinically using the modified United States Public Health Service criteria. Amalgam restorations (104 weeks) showed the highest survival time followed by glass ionomer ( 87 weeks), composite ( 84 weeks) and stainless steel crown ( 79 weeks). Glass ionomer showed the highest survival time for class I but for class II, it was amalgam. This results indicates that the type of material influences the survival rate of restorations.
\end{abstract}

(C) 2019 Elsevier Ltd. All rights reserved.

Selection and/or Peer-review under responsibility of Biomedical and Advanced Materials (Biocam 2017).

Keywords: Primary molar restorations; longevity; survival time

\section{Introduction}

Dental caries remains a major public health problem in most countries of the world. Available data indicates that there is a marked increase in the prevalence of dental caries globally [1].

In Malaysia, caries continues to be a major challenge especially in primary tooth. Caries prevalence among 6-year olds is $74.5 \%$ in 2007 [2,3] and among 5 year olds, it is $76.2 \%$ in 2005 [3,4]. The mean decayed, missing, and filled teeth (dmft) score was 5.6 and about $55.8 \%$ of the 5 year-olds had 3 or more deciduous teeth affected by caries

\footnotetext{
* Corresponding author. Tel.: +09-5705466; fax: +09-5716779.

E-mail address: norasilah@iium.edu.my.
} 
whilst $25.3 \%$ had $\mathrm{dmft} \geqslant 10[3,4]$. Caries need to be treated, otherwise it can cause problems especially to young children. Severe caries problem will lead to tooth pain and infection which will disturb sleep and eating, leading to malnutrition and attendance problem in school $[5,6,7]$. Primary teeth is important as space maintainer for permanent tooth. Early extraction of primary teeth can cause orthodontics problem later in life [8].

Effective restorative intervention plays an important role in the management of carious teeth [9]. Restoration in primary teeth should have appropriate function and aesthetics until tooth exfoliation [10]. Longevity of restorative intervention is dependent on many factors such as the characteristics of the tooth itself, the site and size of the cavity, the patient, dentist experience and clinical skill, and the materials used [11,12]. For effective restoration, it should have longer longevity and higher survival rate.

There are several restorative materials indicated for primary molars restoration; amalgam, stainless steel crowns, composite resin, glass ionomer, resin modified glass ionomer cements (RMGICs) and polyacid-modified composite resin or compomer [13], depending on the suitability of cavity design and cooperation of the patient. The success of restoration depends on the restorative material factors such as resistance to wear, fracture and marginal breakdown, adhesion to tooth structure and easy to manipulate as well as operator skill [14].

Given the above scenario of high prevalence of caries, in order to maintain primary teeth and requirement for the management of caries in children, oral health professionals need to make wise decisions about the type of restorative material they choose to best manage their patients.

Decision on the best type of restorative material in a particular situation depends on the clinical performance of each type of the material but lack of evidence persists. Hence, the aim of this study is to determine the clinical performance of different types of restorative materials placed in primary molars.

\section{Methods}

The study has been approved by IIUM Research Ethics Committee (IREC) on 8 April 2014 (Project number IREC 273). It is a retrospective study conducted at the Student Polyclinic, Kulliyyah of Dentistry, International Islamic University Malaysia. A total of 115 primary molar restorations from 32 healthy children aged between 5 to 12 years old were evaluated for their clinical performance.

The restorations were placed by undergraduate dental students under paediatric dental specialist supervision. The materials used for the restoration were either pre-fabricated stainless steel crown, self-cure glass ionmer cement for posterior tooth, dental amalgam and light-cure resin based composite for posterior tooth.

All of the participants in this study had consented by their legal guardian or parents. The data was collected from June 2014 to October 2014 during a clinical review after 6 to 36 months of restorations placement. The restorations were evaluated clinically using the modified United States Public Health Service criteria for clinical performance of dental restorations.

Clinical examination was conducted by three examiners which had been calibrated with a paediatric dental specialist before the data was collected. Inter and intra-examiners reliability statistically evaluated using kappa test for various recordings ranged and it was more than 0.80 .

In the criteria used, marginal and approximal adaptation, anatomical form and signs of secondary caries were judged according to a four-grade scale as stated in Table 1.

For adaptation and anatomical form, the scale of 1 and 2 is considered acceptable or successful, otherwise 3 and 4 are considered as failure. For secondary caries, scale 1 was considered acceptable or successful while scale 2 was considered as failure. For any restorations detected with one of the criteria fails, or more than one fail, the restoration is considered a failure.

The longevity of the restorations was detected by determining the date of the restorations placed, date of the restorations being reviewed, type of restorative material used and the type of the cavity prepared. Thus the period of restorations was calculated and the success criteria of restorations checked. 
Table 1. Ryge criteria according to the United States of Public Health Services guidelines ( 1 and 2 are considered acceptable or successful, 3 and 4 as failure, exceptional for scale 1 caries is considered acceptable or successful while 2 is considered as failure).

\begin{tabular}{|c|c|c|c|}
\hline $\begin{array}{l}\text { Ryge criteria according to } \\
\text { USPHS guidelines }\end{array}$ & Marginal adaptation & Anatomical form & Secondary caries \\
\hline 1 & $\begin{array}{l}\text { Restoration adapts closely to the } \\
\text { tooth along margins }\end{array}$ & $\begin{array}{l}\text { Good anatomic form with } \\
\text { optimal approximal }\end{array}$ & Not observed (acceptable) \\
\hline 2 & $\begin{array}{l}\text { Clinically insignificant gap } \\
\text { between restoration }\end{array}$ & $\begin{array}{l}\text { Clinically acceptable shape with } \\
\text { acceptable approximal }\end{array}$ & $\begin{array}{l}\text { Present clinically and/or } \\
\text { radiographically (not acceptable) }\end{array}$ \\
\hline & and cavity margins & Contact & \\
\hline 3 & $\begin{array}{l}\text { Poor marginal adaptation with } \\
\text { obvious gap with/without caries. } \\
\text { Restoration needs replacement }\end{array}$ & $\begin{array}{l}\text { Insufficient approximal contact } \\
\text { resulting in food } \\
\text { impaction }\end{array}$ & \\
\hline 4 & Loss of restoration & No approximal contact & \\
\hline
\end{tabular}

\section{Statistical Analysis}

Survival analysis was chosen to analyze the data for this study whereby Kaplan Meier was used for nonparametric and Cox regression for semi-parametric type of survival analysis.

Life tables is a descriptive procedure for examining the distribution of time-to-event variables to subdivide the period of observation into smaller time intervals. Thus, the probability from each interval was estimated. The assumption is the probability for the restorative materials depends on time measured weeks.

\section{Results}

\section{a. Overall success rate of primary molar restorations}

Reviews were conducted on 115 primary molar restorations placed by the undergraduate dental students from 32 healthy children aged between 4 to 12 years old. The restorations were aged between 33 weeks ( $~ 8$ months) to 141 weeks ( $\sim 35$ months) during data collection. From the 115 restorations, there were 29 GIC restorations $(25 \%), 55$ composite restorations (48\%), 15 amalgam restorations (13\%), and $16 \mathrm{SSC}(14 \%)$.

Based on Table 2, amalgam restorations showed the largest median survival time in weeks which is 104 weeks. This indicated that amalgam has the longest longevity, followed by glass ionomer cement with relatively 87 weeks, composite with relatively 84 weeks and stainless steel crown with 79 weeks.

Table 2. Median Survival Time (Weeks).

\begin{tabular}{cc}
\hline Materials & Median Time (weeks) \\
\hline GIC & 86.78 \\
Composite & 83.78 \\
Amalgam & 104.00 \\
SSC & 79.00 \\
\hline
\end{tabular}

\section{b. Comparison of primary molar restorations' clinical performance in different types of classes}

Table 3 shows the total number of restorations according to the types of restorative material used and the number of failure without concerning the period of the restorations was placed. For Class I and Class II restoration, amalgam 
showed the highest percentage of success $(85.7 \%$ and $75.0 \%)$ but for more than 2 surfaces restoration, stainless steel crown had the highest percentage of success $(87.5 \%)$. For the overall comparison between Class I and Class II, Class II had the highest percentage of failure.

Table 3. Number of restorations and failure.

\begin{tabular}{|c|c|c|c|c|c|}
\hline Class/surfaces & Materials & Total of restoration & Failure & Success & Percentage \\
\hline \multirow[t]{2}{*}{ More than 2} & $\mathrm{SSC}$ & 16 & 2 & 14 & $87.5 \%$ \\
\hline & Overall & 16 & 2 & 14 & $87.5 \%$ \\
\hline \multirow[t]{4}{*}{1} & GIC & 14 & 5 & 9 & $64.3 \%$ \\
\hline & $\mathrm{CR}$ & 36 & 8 & 28 & $77.8 \%$ \\
\hline & $\mathrm{AR}$ & 7 & 1 & 6 & $85.7 \%$ \\
\hline & Overall & 57 & 14 & 43 & $75.4 \%$ \\
\hline \multirow[t]{4}{*}{2} & GIC & 15 & 13 & 2 & $13.3 \%$ \\
\hline & $\mathrm{CR}$ & 19 & 12 & 7 & $36.8 \%$ \\
\hline & $\mathrm{AR}$ & 8 & 2 & 6 & $75.0 \%$ \\
\hline & Overall & 42 & 27 & 15 & $35.7 \%$ \\
\hline Overall & Overall & 115 & 43 & 72 & $62.6 \%$ \\
\hline
\end{tabular}

Table 4 shows that when the duration of restoration were placed with $95 \%$ confidence interval, mean for survival time for more than two surfaces restorations is relatively 91 weeks. In class I restorations, glass ionomer cement shows the highest mean for survival time which is relatively 119 weeks, followed by composite and amalgam. Amalgam shows the lowest mean for survival time which is relatively 97 weeks. Based on Table 5, there is no statistically significant difference between different types of restorations in class I and class II.

Table 4. Means for Survival Time.

\begin{tabular}{cccccc}
\hline \multicolumn{5}{c}{} & \multicolumn{5}{c}{ Means $^{\mathrm{a}}$} \\
\hline \multirow{2}{*}{ More than 2 } & & & \multicolumn{2}{c}{$95 \%$ Confidence Interval } \\
& SSC & 91.000 & 11.025 & 69.391 & Upper Bound \\
& Overall & 91.000 & 11.025 & 69.391 & 112.609 \\
1 & Overall & 115.060 & 6.098 & 103.109 & 112.609 \\
& GIC & 118.714 & 11.003 & 97.149 & 127.012 \\
& CR & 106.724 & 7.037 & 92.931 & 120.280 \\
& AR & 96.857 & 9.390 & 78.452 & 115.262 \\
& Overall & 79.960 & 5.225 & 69.719 & 90.201 \\
& GIC & 79.006 & 7.602 & 64.105 & 93.906 \\
& CR & 71.500 & 6.085 & 59.573 & 83.426 \\
& AR & 89.389 & 9.503 & 70.764 & 108.014 \\
& Overall & 98.731 & 4.391 & 90.125 & 107.338 \\
\hline
\end{tabular}

a. Estimation is limited to the largest survival time when censored.

Table 5. Overall Comparisons.

\begin{tabular}{llrrr}
\hline Class & & Chi-Square & Df & Sig. \\
\hline More than 2 & Log Rank (Mantel-Cox) &. & 0 &. \\
1 & Log Rank (Mantel-Cox) & .480 & 2 & .787 \\
2 & Log Rank (Mantel-Cox) & 3.280 & 2 & .194 \\
\hline
\end{tabular}

Note: Test of equality of survival distributions for the different levels of materials. 
Fig. 1 shows the survival plot for stainless steel crown restorations. Fig. 2 shows the survival plot for amalgam, composite and glass ionomer cement in class I restorations. Amalgam survival rate in class I decreased for below 40 weeks but maintained higher than 0.8 for the rest of the weeks.

Composite survival rate decreased in more than 40 weeks and less than 60 weeks and had continued to decrease until maintaining at 80 weeks and above. Glass ionomer cement decreased at less than 60 weeks and continued to decrease to 140 weeks. Fig. 3 shows the survival plot for amalgam, composite and glass ionomer cement in class II restorations.

Amalgam survival rate in class II decreased in less than 50 weeks and continued to decline until maintaining at more than 75 weeks but less than 100 weeks. Composite survival rate continued to decline gradually for more than 100 weeks. Glass ionomer cement continued to decline for more than 125 weeks.

\section{Survival Functions}

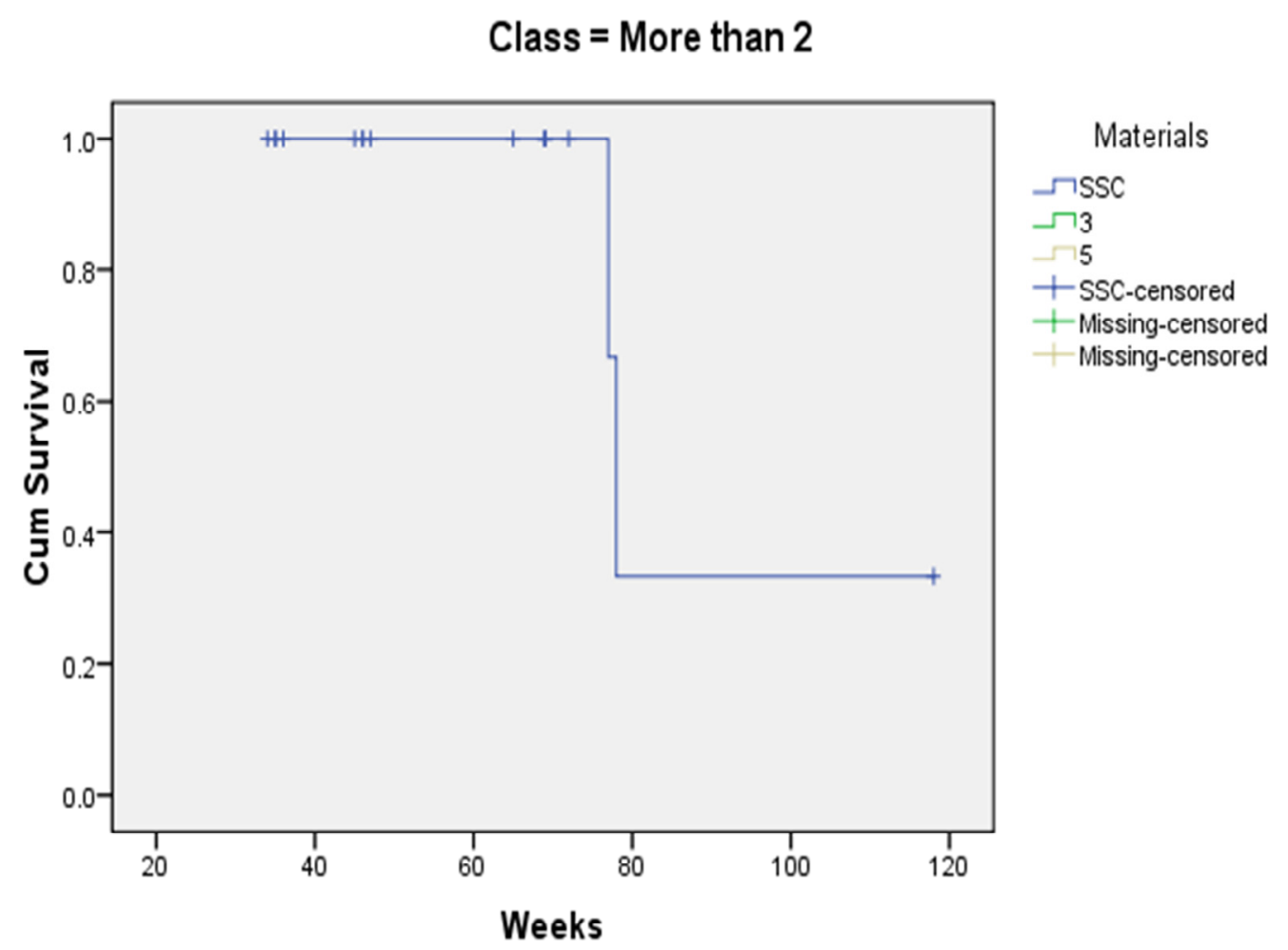

Fig. 1. Survival Plot for Comparison of the Restoration Class. 


\section{Survival Functions}

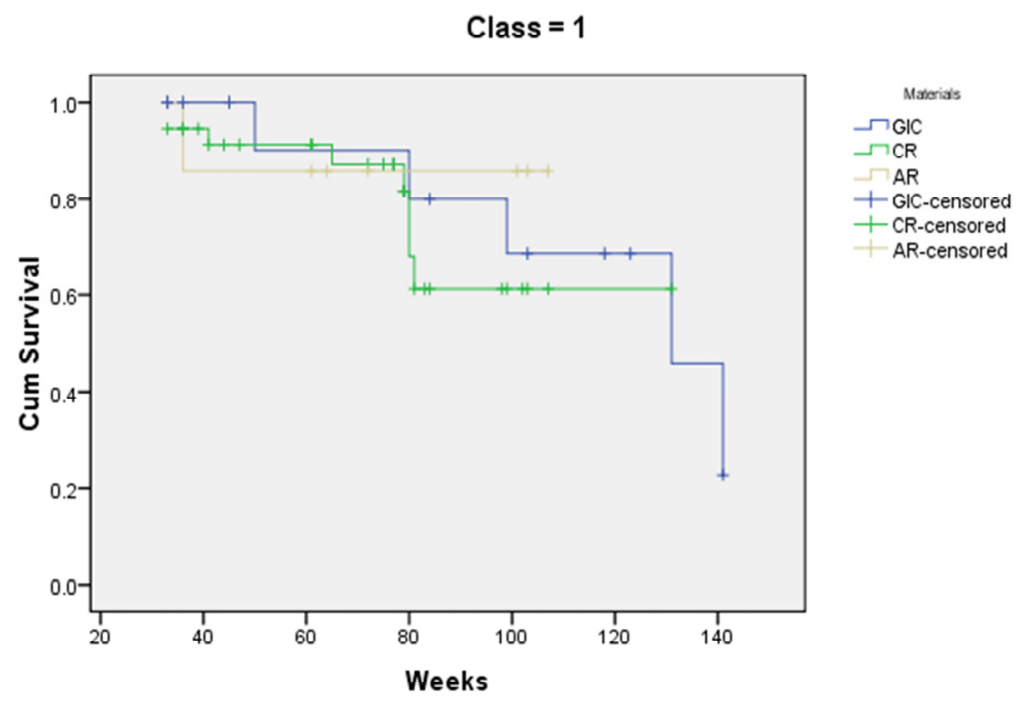

Fig. 2. Survival Plot for Comparison of the Restoration Class.

\section{Survival Functions}

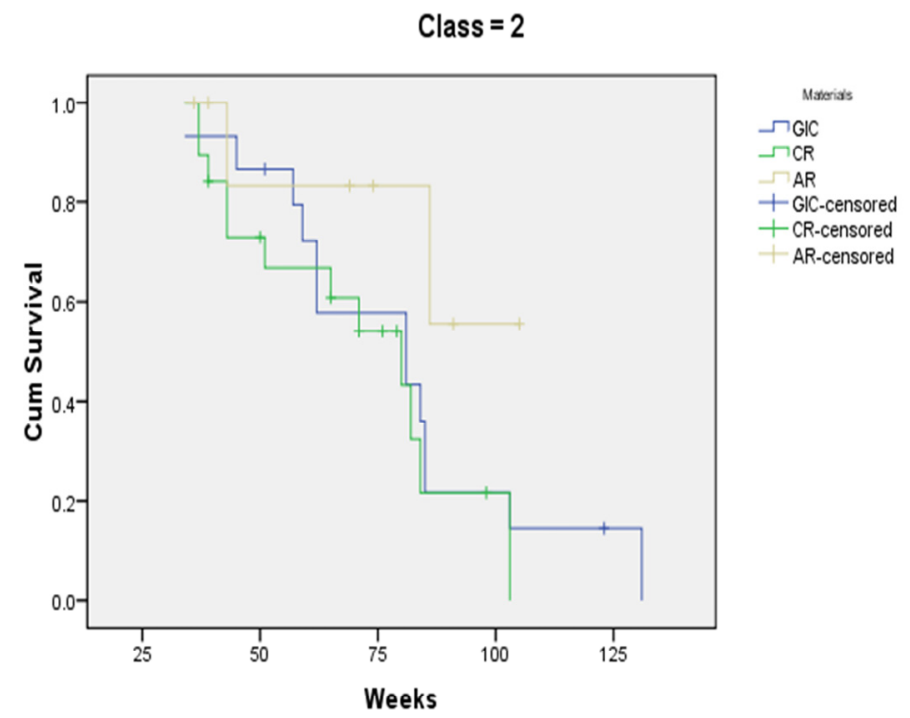

Fig. 3. Survival Plot for Comparison of the Restoration Class. 


\section{Discussion}

Modified Ryge criteria from USPHS guidelines had been used to evaluate the restorations in this study. These criteria had been used in the majority of clinical research before and reliable criteria to be used in evaluating restorations [15,16,17]. However, the criteria did not have any radiograph examination. The radiograph of restoration is crucial especially in the diagnosis of secondary caries.

In this study, the operators were the undergraduate dental students which had a minimum amount of clinical exposure, experience and clinical skill. The result shows that amalgam provided superior results followed by GIC and composite. This indicates that the clinical skill of dental student is sufficient because amalgam is easier to manipulate and is less technique sensitive as compared to other materials. Materials that are technique sensitive and difficult to manipulate had a lower success rate compared to less technique sensitive and easy to manipulate materials $[12,18]$.

This is a retrospective study whereby the restoration had already been placed prior to the clinical examination for data collection. This situation eliminated the Hawthorne effect, thus the results of this study are more reliable. Studies have shown that participants are more likely to change their behavior in response to their awareness of being observed [19,20]. In this study, participants were not aware that they are being observed until they were informed during the reviewed visit. Thus, the issue of habit and behavior change was eliminated prior to data collection.

Following the Minamata Convention on Mercury in 2013, the use of mercury should be phased out which includes the reduced use of mercury in dental amalgam. Upon signing the text of Convention on 24 September 2014, Malaysia has accepted the requirements stated in the Convention.

A phase-down in the use of amalgam especially in dental school teaching and continuing professional development (CPD) is necessary in order to make sure the implementation of this international agreement is successful [21]. This is the reason why the amalgam used especially in dental school has been reduced slowly. Therefore, it is essential to find a restorative material that is comparable to amalgam.

Amalgam had been proven since long time ago to have the longest survival period and longevity as compared to composite and GIC $[22,23,24,25,26]$.

this study, amalgam had also shown to have the highest median survival time (104.0 weeks) followed by GIC ( 86.78 weeks) and composite ( 83.78 weeks). For the overall comparison between types of cavity, class II cavity had the highest percentage of failure and amalgam showed to have the longest survival time in class II. A smaller restoration would produce a higher chance of survival. The survival rate of class I is more than class II because it involves two surfaces [11,27].

Overall for this study, the best restorative material for primary molar restoration is amalgam. However, glass ionomer cement is the best restorative material for class I while for class II, amalgam is the best restorative material. Unlike composite, amalgam and glass ionomer cement require less-sensitive techniques. It shows that amalgam and glass ionomer cement are still not comparable to amalgam and there is a need to improve the quality of each material.

\section{Conclusion}

The result shows that the type of material influences the survival rate of primary molar restorations.For class I restoration, it is found that GIC material shows better results compared to composite and amalgam. For class II restoration, amalgam gives a better result compared to GIC and composite.This study shows overall, amalgam restoration gives a superior result.

\section{Acknowledgements}

We would like to thank Kulliyyah of Dentistry, IIUM Kuantan Campus, Malaysia for their enormous support to this study. The publication of this study was funded by IIUM RIGS16-328-0492. 


\section{References}

[1] R.A. Bagramian, F. Garcia-Godoy, A.R. Volpe, The global increase in dental caries. A pending public health crisis. Am. J. Den. 22 (2009) 3-8.

[2] Ministry of Health Malaysia, National oral health survey of schoolchildren 2007 (NOHSS 2007): 6 year olds: Report, Ministry of Health Malaysia, Kuala Lumpur, 2007.

[3] Ministry of Health Malaysia, A lifetime of healthy smiles: National oral health plan for Malaysia 2011-2020, http://ohd.moh.gov.my/v3/images/nohp20112020.pdf, 2011 (accessed 27 December 2017).

[4] Ministry of Health Malaysia, National oral health survey of preschool children 2005 (NOHPS 2005). https://www.mah.se/upload/FAKULTETER/OD/Avdelningar/who/WPRO/Malaysia/data/oral_healthcare_for_the_pre-school_children.pdf, 2005 (accessed 27 December 2017).

[5] A.S. Daar et al., Grand challenges in chronic non-communicable diseases. Nat. 450 (2007) 494.

[6] W. Marcenes et al., Global burden of oral conditions in 1990-2010: A systematic analysis. J. Dent. Res. 92 (2013) $592-597$.

[7] A. Alm et al., Caries in adolescence-Influence from early childhood. Community Dent. Oral Epidemiol. 40 (2012) $125-133$.

[8] W. Tunison et al., Dental arch space changes following premature loss of primary first molars: A systematic review. Pediatr. Dent. 30 (2008) 297-302.

[9] T. Kandiah, J. Johnson, S.A. Fayle, British society of paediatric dentistry: A policy document on management of caries in the primary dentition. Int. J. Paediatr. Dent. 11 (2010) 153-157.

[10] L. Casagrande et al., Randomized clinical trial of adhesive restorations in primary molars. 18-month results. Am. J. Dent. 26 (2013) $351-$ 355.

[11] J.F. Roberts, N. Attari, M. Sherriff, The survival of resin modified glass ionomer and stainless steel crown restorations in primary molars, placed in a specialist paediatric dental practice. Br. Dent. J. 198 (2005) 427-431.

[12] F.F. Demarco, Longevity of posterior composite restorations: Not only a matter of materials. Dent Mater. 28 (2012) 87-101.

[13] R. Welbury, M.S. Duggal, M.T. Hosey, Paediatric Dentistry, fourth ed., Oxford University Press, Oxford, 2012.

[14] L. Giachetti, Influence of operator skill on microleakege of total-etch and self-etch bonding systems. J. Dent. 36 (2008) $49-53$.

[15] J. Estay et al., Effect of refurbishing amalgam and resin composite restorations after 12 years: Controlled clinical trial. Oper. Dent. 42 (2017) 587-595.

[16] H. Priyank et al., In vitro comparative evaluation of various restorative materials used for restoring Class III cavities in deciduous anterior teeth: A clinical study. J. Contemp. Dent. Pract. 17 (2016) 1022-1026.

[17] F. Schwendicke et al., Selective or stepwise removal of deep caries in deciduous molars: Study protocol for a randomized controlled trial. Trails 16 (2015) 11.

[18] N. J. Opdam et al., A retrospective clinical study on longevity of posterior composite and amalgam restorations. Dent. Mater. 23 (2007) $2-8$.

[19] N.S. Fox NS et al., Clinical estimation of fetal weight and the Hawthorne effect Eur. J. Obstet. Gynecol. Reprod. Biol. 141 (2008) 111-114.

[20] J. McCambridge, J. Witton, D.R. Elbourne, Systematic review of the Hawthorne effect: new concepts are needed to study research participation effects. J. Clin. Epidemiol. 67 (2014) 267-277.

[21] C.D. Lynch, N.H. Wilson, Managing the phase-down of amalgam: Part I. Educational and training issues. Br. Dent. J. 215 (2013) $109-113$.

[22] R.R.Welbury RR et al., The 5-year results of a clinical trial comparing a glass polyalkenoate (ionomer) cement restoration with an amalgam restoration. Br. Dent. J. 170 (1991) 177-181.

[23] V. Qvist et al., Longevity and cariostatic effects of everyday conventional glass-ionomer and amalgam restorations in primary teeth: Threeyear results. J. Dent. Res. 76 (1997) 1387-1396.

[24] J.A. Soncini et al. The longevity of amalgam versus compomer/composite restorations in posterior primary and permanent teeth: Findings From the New England Children's amalgam trial. J. Am. Dent. Assoc. 138 (2007) 763-772.

[25] M. Bernardo, Survival and reasons for failure of amalgam versus composite posterior restorations placed in a randomized clinical trial. J. Am.

Dent. Assoc. 138 (2007) 775-783.

[26] M.G. Rasines Alcaraz et al., Direct composite resin fillings versus amalgam fillings for permanent or adult posterior teeth. Cochrane Database

Syst. Rev. 31 (2014) CD005620.

[27] N.K. Ersin et al., A clinical evaluation of resin-based composite and glass ionomer cement restorations placed in primary teeth using the ART approach: Results at 24 months. J. Am. Dent. Assoc. 137 (2006) 1529-1536. 